\title{
Empirical study on the sound insulation of wooden lightweight frame floors
}

\author{
Lukasz Nowotny ${ }^{1, *}$, Jacek Nurzyński ${ }^{1}$ \\ ${ }^{1}$ Building Research Institute, Department of Thermal Physics, Acoustics and Environment, Poland
}

\begin{abstract}
Lightweight frame structures become increasingly popular in housing. They are used in single-, as well as multifamily, residential buildings. Such a tendency is in the line with sustainable development and the need for energy conservation. Lightweight frame partitions provide a certain comfort of life and remain environmentally friendly. However, they are tricky in terms of acoustics. Different factors and technical details influence their sound insulation. The paper presents the analysis of the acoustical effects resulting from different layers used on lightweight frame floors. Airborne, as well as impact sound insulation, have been considered, based on the results of laboratory measurements according to ISO 10140 standard.
\end{abstract}

\section{Introduction}

The growing interest in lightweight structures used in residential buildings is evidently observed in recent years, wood frame as well as the other lightweight solutions are considered [1]. One of the basic reasons for this concern is the need for ecological and energy-saving technologies, ensuring reduction of $\mathrm{CO}_{2}$ emissions to the atmosphere. Construction sector, including the production of building materials, is one of the biggest "polluters" of the natural environment. Lightweight structures, in comparison with massive, traditional buildings, are perceived as more friendly to the environment and giving possible high level of life comfort. They are pretty well identified in terms of static or thermal behaviour, whereas their airborne and impact sound insulation is distinctly more complicated and unrecognized. Acoustic performance of a dwelling is one of the main points contributing to its general quality level and the inhabitants' opinion on living conditions at home. Even small structural details seriously influence the acoustic properties of lightweight buildings [2].

The aim of this study was to analyze the acoustical effects caused by different insulating layers used on the basic structure of lightweight frame floor, and to collect data for further simulations and acoustic performance prediction of frame floors, particularly in terms of impact sound insulation. The investigated basic floor refers to the standard floor type $\mathrm{C} 2$ designed to measuring the improvement of impact sound insulation according to ISO 10140 standard. Airborne and impact sound insulation for each of tested floor models have been

*Corresponding author:1.nowotny@itb.p1 
considered equally based on the results of laboratory measurements carried out according to ISO 10140.

\section{Test object}

Six different models of a wooden floor with dimensions of $4230 \mathrm{~mm}$ x $2740 \mathrm{~mm}$ were tested in a horizontal opening of the standard acoustic test facilities. The basic structure of the floor was made of $60 \mathrm{~mm} \times 240 \mathrm{~mm}$ wooden joists with a distance between then of $680 \mathrm{~mm}$, covered with $22 \mathrm{~mm}$ OSB panels screwed directly to the joists (model 1 in figure 1). Then the wooden grid was filled with $100 \mathrm{~mm}$ of mineral wool secured in place with a wire formed into a grid and finished on the bottom side with $12,5 \mathrm{~mm}$ plasterboard panels attached to the wooden grid via aluminium profile connectors (model 2 in figure 1). Models 3 and 4 were constructed by putting heavy floating floor made of mineral wool and self-leveling screed cast on the top of the previous structure. Two types of floor were considered, equipped with $25 \mathrm{~mm}$ and $60 \mathrm{~mm}$ upper slab respectively (fig. 2). In the case of models 5 and 6, the heavy floating floors were removed and the basic floor structure was modified by cutting OSB panels into smaller pieces and installing them between joists (fig. 3). The pockets, that have been form in that way, were filled with $130 \mathrm{~mm}$ layer of expanded clay aggregate, overtopping the joists. In model 5 the aggregate was covered directly with 22-milimeter dry screed boards (model 5 in Fig. 3), when model 6 was rearranged by installing $20 \mathrm{~mm}$ heavy mineral wool beneath these upper boards (model 6 in Fig. 3).

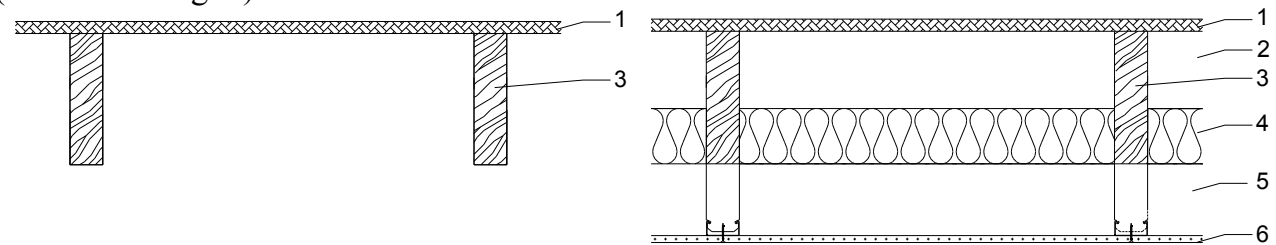

Fig. 1. Vertical sections of model 1 (left) and 2 (right) of the wooden frame floor. $\left(1-O S B\right.$ board, 2 - air gap, 3 - wooden joints, 4 - mineral wool $\rho=12 \mathrm{~kg} / \mathrm{m}^{3}, 5$ - air gap, 6 - plaster board.
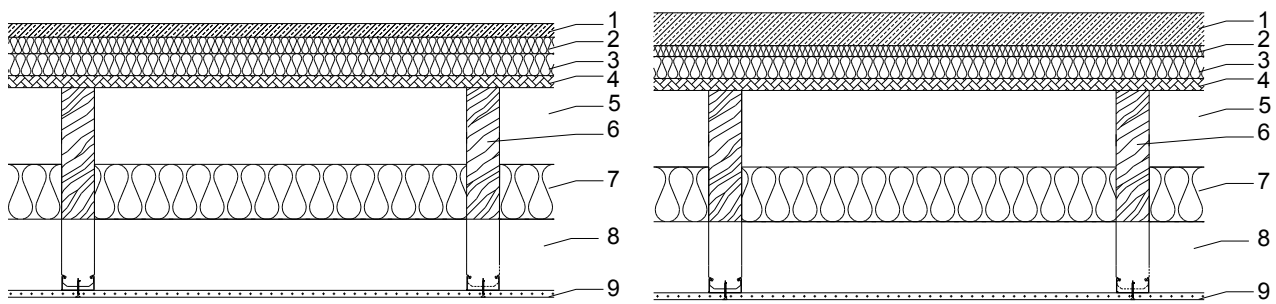

Fig. 2. Vertical sections of model 3 (left) and 4 (right) of the wooden frame floor. $\left(1\right.$ - self-leveling screed, $2-$ mineral wool $\rho=150 \mathrm{~kg} / \mathrm{m}^{3}, 3-$ mineral wool $\rho=107 \mathrm{~kg} / \mathrm{m}^{3}, 4-O S B$ board, 5 - air gap, 6 -wooden joints, 7 - mineral wool $\rho=12 \mathrm{~kg} / \mathrm{m}^{3}, 8$-air gap, 9 - plaster board.
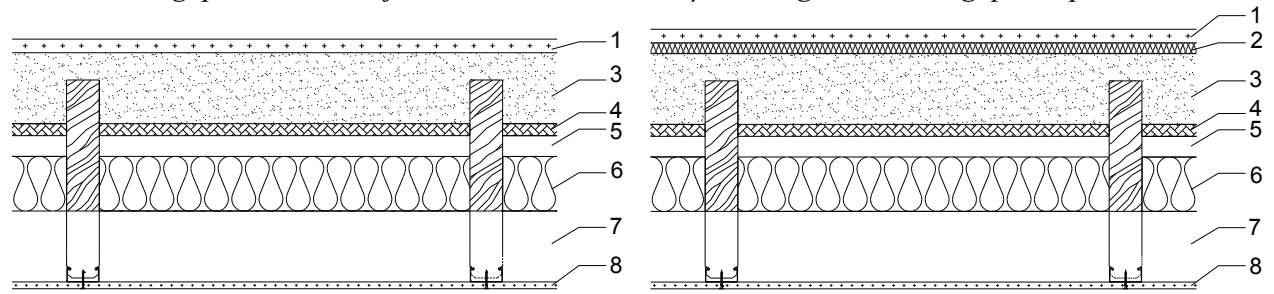

Fig. 3. Vertical section of model 5 (left) and 6 (right) of the wooden frame floor. $\left(1-d r y\right.$ screed board, 2 - mineral wool $\rho=150 \mathrm{~kg} / \mathrm{m}^{3}, 3$ - expanded clay aggregate, 4 - OSB board, 5 -air gap, 6 - mineral wool $\rho=12 \mathrm{~kg} / \mathrm{m}^{3}, 7$-air gap, 8 - plaster board. 


\section{Measurement setup and procedures}

Airborne and impact sound insulation tests were carried out in accordance with PN-EN ISO 10140 standard, while the single number values were calculated according to PN-EN ISO 717-1 and PN-EN ISO 717-2 respectively. As the airborne pink noise sources two wideband speaker cabinets placed in the corners of the source room were used. For the impact sound insulation measurements standard tapping machine was used, placed in five positions on the floor, in accordance with the standard's recommendations. Average sound pressure levels in $1 / 3$ octave bands were measured in the source and receiving room. Continuously moving microphones were used for the space averaging; the sound pressure level was integrated over time and space. Reverberation time was determined in the receiving room to enable the calculation of sound reduction index $R$, as well as the normalized impact sound pressure level, $\mathrm{L}_{\mathrm{n}}$. The source and receiving rooms have irregular shape with no parallel walls and they are separated by a structural acoustic break.

\section{Sound insulation test results}

\subsection{Basic construction of the wooden floor}

The results of laboratory measurements taken for the basic floor (model 1) and the floor with suspended ceiling (model 2) are presented in figure 4 . The single number values of airborne and impact sound insulation are collected in table 1. The acoustic performance of bare floor is poor and it is obvious, that the improvement should be assured by using adequate additional insulating layers [3].

Table 1. Single-number quantities of wooden frame floors.

\begin{tabular}{|c|c|c|c|c|c|c|}
\hline Index & Model 1 & Model 2 & Model 3 & Model 4 & Model 5 & Model 6 \\
\hline \hline $\mathrm{R}_{\mathrm{w}}, \mathrm{dB}$ & 24 & 44 & 57 & 58 & 59 & 61 \\
\hline $\mathrm{C}, \mathrm{dB}$ & -1 & -2 & -5 & -3 & -2 & -1 \\
\hline $\mathrm{C}_{50-5000}, \mathrm{~dB}$ & 0 & -4 & -12 & -6 & -8 & -12 \\
\hline \hline $\mathrm{L}_{\mathrm{n}, \mathrm{w}}, \mathrm{dB}$ & 92 & 73 & 59 & 60 & 60 & 50 \\
\hline $\mathrm{C}_{\mathrm{l}}, \mathrm{dB}$ & -3 & 0 & 4 & 3 & 2 & 5 \\
\hline $\mathrm{C}_{50-3150}, \mathrm{~dB}$ & -3 & 2 & 6 & 6 & 4 & 11 \\
\hline
\end{tabular}
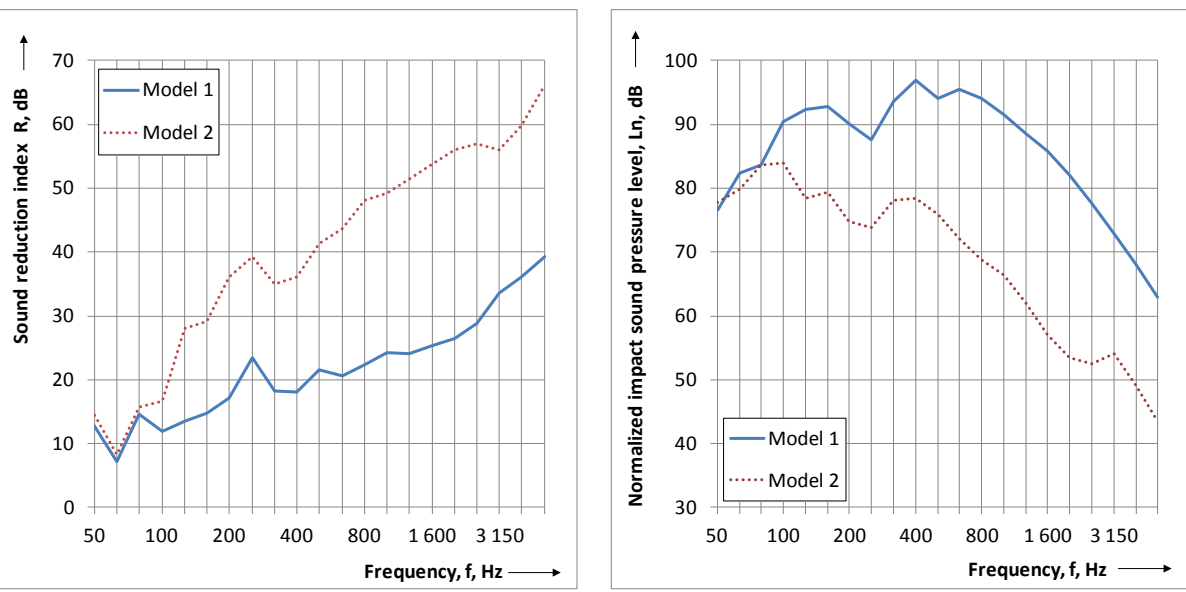

Fig. 4. Airborne (left) and impact (right) sound insulation test results of the basic construction of the wooden floor. 
The application of suspended ceiling increases the values of single number indicators by about $20 \mathrm{~dB}$ for airborne as well as impact sound insulation. However, still they are not satisfying even for inhabitants with very low expectations [4]. The specific behaviour can be observed in $250 \mathrm{~Hz}$ band for both structures, with and without the ceiling, and in both areas - airborne and impact sound insulation (fig. 4). Possible explanation for this phenomenon might be found in distance between wooden joists used in basic construction of the floor, which is $62 \mathrm{~cm}$, close to the half of the $250 \mathrm{~Hz}$ wave length and to the $500 \mathrm{~Hz}$ full wave length. Wooden joists together with OSB panels create a row of resonators which damped above frequencies what results in increased sound insulation.

\subsection{Heavy floating floors}

Basic floor with suspended ceiling (model 2) has been equipped successively with two different heavy floating floors made of self-leveling screed (model 3 and 4). Technical data on components constituting the upper layers is specified in Tab. 2. The results of the laboratory sound insulation measurements are shown in Fig. 5, while the single number values are given in table 1 . The airborne sound insulation is quite promising. However the negative values of spectrum adaptation terms are rather high, particularly when the enlarged range of frequency is considered (table 1). The values of $R_{w}$ index are quite the same for both models, but the solution with thicker slab is more favourable if term $\mathrm{C}$ is employed for the assessment.

Impact sound insulation of model 3 and 4 is also similar. However the values still are too high to be satisfying in multifamily residential building. Besides, the positive values of term $\mathrm{C}_{\mathrm{I}}$ indicate, that the low frequency performance may pose a problem.

Table 2. Specification of the floating floors built on a basic construction of wooden frame floor.

\begin{tabular}{|c|c|c|}
\hline Layers (from the top to the bottom) & Model 3 & Model 4 \\
\hline \hline Self-leveling screed, $\mathrm{mm}$ & 25 & 60 \\
\hline Polyethylene film, $\mathrm{mm}$ & 0,5 & 0,5 \\
\hline Mineral wool $(1)\left(150 \mathrm{~kg} / \mathrm{m}^{3}\right), \mathrm{mm}$ & 30 & 20 \\
\hline Mineral wool $(2)\left(107 \mathrm{~kg} / \mathrm{m}^{3}\right), \mathrm{mm}$ & 40 & 40 \\
\hline
\end{tabular}
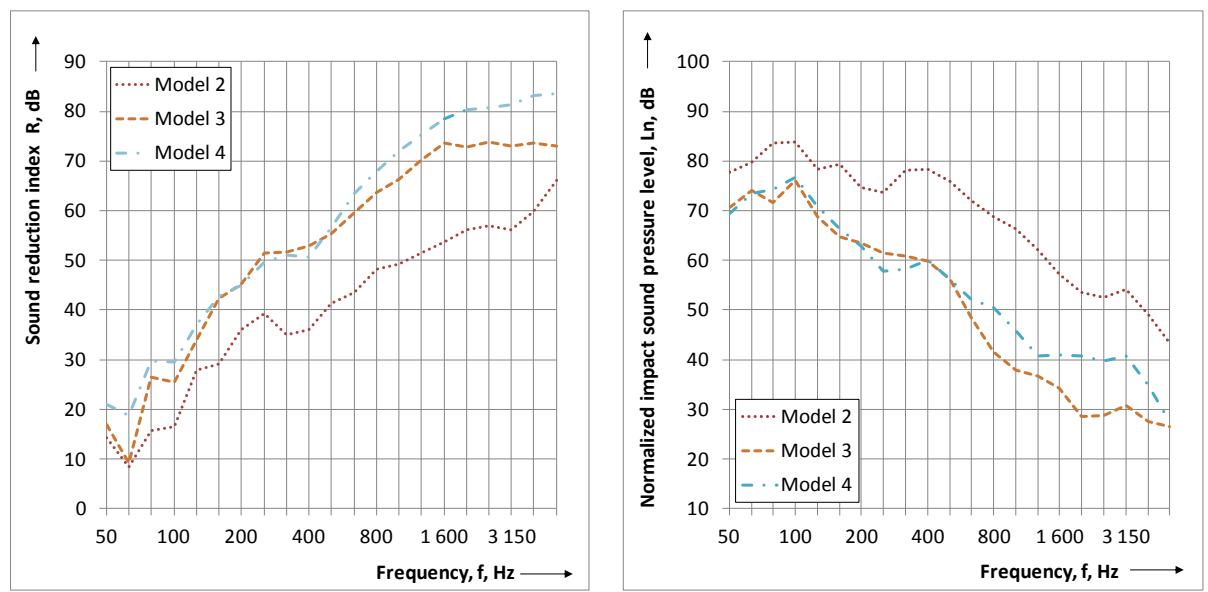

Fig. 5. Airborne (left) and impact (right) sound insulation test results of the model 3 and 4 of the wooden floor compared to the basic construction (model 2). 
Increased mass, resulting from different thickness of an upper slab (25 and $60 \mathrm{~mm}$ ), did not improve the sound insulation very much. It brings about better airborne sound insulation in the low frequency area, which results in higher values of $\mathrm{R}_{\mathrm{w}}+\mathrm{C}_{50-5000}$ index. In category of impact sound insulation both solutions gives more or less the same results. Thicker construction gives slightly worse values in higher frequencies what results in higher single number quantity, $\mathrm{L}_{\mathrm{n}}$. From this it follows that the optimization of the slab thickness on lightweight construction is possible and it does not behave the same as on the massive floor [5].

Increased sound insulation in $250 \mathrm{~Hz}$ frequency band that was observed in the case of bare floors can be also noticed for the floor with heavy floating floors. That might confirm observations that it is the result of resonances that are formed below the OSB panels.

Airborne sound insulation was tested successively during the curing time of the floating floor screed. Measurements were carried out in a one week intervals, only minor changes were observed; model 4 shows small improvement in frequencies above $800 \mathrm{~Hz}$ along with the screed aging. After four weeks impact sound insulation was also tested in a one week intervals, no changes had been observed during that time.

\subsection{Lightweight floating floors}

Heavy floating floors were replaced with lightweight systems made of expanded clay aggregate and dry screed boards on the top (model 5 and 6). The OSB panels were cut into smaller boards and placed between wooden joists, making more space for the loosely poured aggregate. The frequency dependent results are presented in Fig. 6, and single number values in table 1 . The floating floor in model 5 has significantly different structure than in models 3 and 4, but the airborne and impact sound insulation is quite similar, even though the dynamic stiffness of the resilient layer is much bigger. Model 6 has an additional layer of the mineral wool under the top slab, which considerably increases the impact sound insulation and also slightly improves the airborne. This might be also an effect of cutting the OSB panels into smaller pieces, which modifies the structural paths of sound transmission, but also changes the static scheme of the floor [6]. And again unfavorable values of spectrum adaptation terms turn our attention to the low frequency behavior.
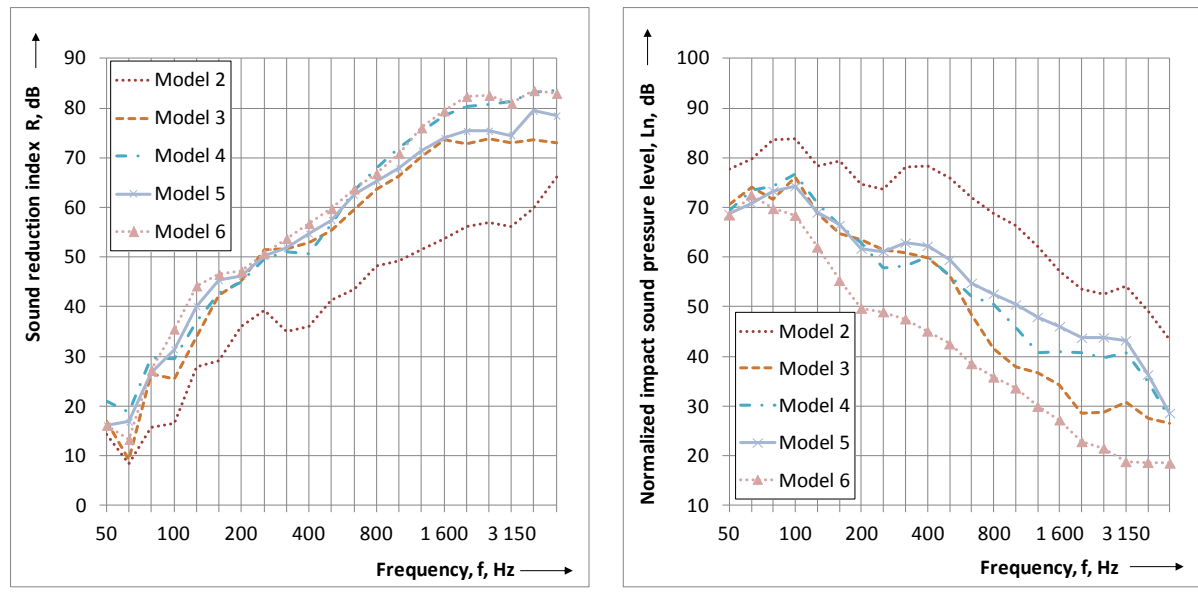

Fig. 6. Airborne (left) and impact (right) sound insulation test results of all models of the wooden floor compared to the basic construction (model 2). 


\section{Conclusions}

Basic construction of the wooden floor has very poor acoustic properties and it cannot be used alone in any building, it needs additional insulating layers. The floating floor and suspended ceiling may improve the sound insulation substantially; critical is the impact sound insulation. Surprising is that the significantly increased thickness (mass) of the upper slab of heavy floating floors hasn't improved its sound insulation very much.

Acoustic properties of a basic floor depend on its geometry, which influence in a way the properties of final construction. Cutting structural board into small pieces and putting them between the joists is profitable in acoustic terms, but changes the static scheme of the floor.

Unfavorable values of spectrum adaptation terms observed in each case, especially when determined in enlarged frequency range, turns the attention to the low frequency problems.

Acoustic data collected for the basic frame floor investigated and the effect of additional layers will be used for further investigations, optimization of lightweight floor structures and prediction of their acoustic performance.

\section{References}

1. J. Nurzyński, Experimental study on the sound insulation of composite panels intended for use in a building, Internoise $2010,39^{\text {th }}$ International Congress and Exposition on Noise Control Engineering. Noise and Sustainability. Proceeding, Lisbon, Portugal, 13-16 June, 2010 s.1-7. Lisboa: Sociedade Portuguesa de Acustica, 2010.

2. L. Degeetere, B. Ingelaerea, New building acoustical concept for lightweight timber frame constructions, Internoise 2014, 43 ${ }^{\text {rd }}$ International Congress on Noise Control Engineering, November 16-19, 2014.

3. A.C.C. Warnock, Controlling the transmission of impact sound through floors, Construction Technology Update No. 35, National Research Council of Canada, 1999.

4. B. N. Gover, J. S. Bradley, S. Schoenwald, B. Zeitler, Subjective ranking of footstep and low-frequency impact sounds on lightweight wood-framed floor assemblies, Forum Acousticum, Aalborg, Denmark, 2011.

5. Ł. Nowotny, Weighted Reduction of Impact Sound Pressure Level for a Floating Floor, According to ISO Standard and Laboratory Measurements, Published in: 2018 Joint Conference - Acoustics, IEEE Xplore Digital Library.

6. J. Nurzyński, P. Poneta, Sound insulation of composite panels based on the laboratory test results. Zeszyty Naukowe Politechniki Rzeszowskiej. Budownictwo i Inżynieria Środowiskowa 2011, nr 276, z.58, nr 3/2011/3, s.115-122. 2011. 